\title{
Usefulness of Spontaneous Speech Analysis Scales in Patients with Mild Cognitive Impairment and Dementia of Alzheimer's Type
}

\author{
Cheon Jin ${ }^{a}$, Hyunjoo Choi ${ }^{\mathrm{b}}$, Jun-Young Lee ${ }^{\mathrm{c}, \mathrm{d}}$ \\ ${ }^{a}$ The Graduate School of Rehabilitation Services, Korea Nazarene University, Cheonan, Korea \\ ${ }^{b}$ Department of Communication Disorders, Korea Nazarene University, Cheonan, Korea \\ 'Department of Psychiatry, Seoul National University College of Medicine, Seoul, Korea \\ ${ }^{d}$ Department of Psychiatry, SMG-SNU Boramae Hospital, Seoul, Korea
}

\author{
Correspondence: Hyunjoo Choi, $\mathrm{PhD}$ \\ Department of Communication Disorders, Korea \\ Nazarene University, 48 Wolbong-ro, Seobuk-gu, \\ Cheonan 31172, Korea \\ Tel: $+82-41-570-1677$ \\ Fax: +82-41-570-7846 \\ E-mail: hjchoi@kornu.ac.kr \\ Received: April 5, 2016 \\ Revised: May 11, 2016 \\ Accepted: May 23, 2016 \\ This work was supported by the National Research \\ Foundation of Korea Grant funded by the Korean \\ Government (NRF-2013S1A5A8023389) and Lee \\ Seung Hwan's Scholarship from the Korean \\ Academy of Speech-Language Pathology and \\ Audiology in 2015.
}

This work was summarized from the master's thesis of the first author (2015)

\begin{abstract}
Objectives: Various scales have been used for analyzing spontaneous speech, but there has been no comparative study on spontaneous speech analysis scales for patients with mild cognitive impairment (MCI) and dementia of Alzheimer's type (DAT). This study aims to examine the usefulness of spontaneous speech analysis scales in patients with $\mathrm{MCl}$ and DAT. Methods: Thirty elderly with normal cognition, 30 patients with $\mathrm{MCl}$, and 30 patients with DAT participated in this study. The Boston Cookie-Theft picture description task was used and analyzed for the ratio of Correct Information Unit (CIU)-morphological words, the ratio of CIU-syntactic words, main concepts, and the number of content words by utterance. Results: The results from this study are as follows. First, the normal cognition group had significantly higher performances only in the number of content words by utterance compared to the $\mathrm{MCl}$ group. Second, the $\mathrm{MCl}$ group had significantly higher performances only in the ratio of CIU-syntactic words than the DAT group. Third, the normal cognition group had significantly higher performances among all spontaneous speech analysis scales than the DAT group. Fourth, the number of content words by utterance was a useful scale for patients with $\mathrm{MCl}$, and the ratio of CIU-syntactic words was a useful scale for patients in the DAT group as shown by results of the ROC curve analysis. Conclusion: The present study suggests that different spontaneous speech analysis scales are useful in discriminating among normal cognition, $\mathrm{MCl}$ and DAT in clinical practice.
\end{abstract}

Keywords: Mild cognitive impairment, Dementia of Alzheimer's type, Picture description, Spontaneous speech analysis scales
알츠하이머형 치매(dementia of Alzheimer's type, DAT) 환자의 언어장애와 관련된 연구들이 활발히 진행되면서, DAT의 조기 진 단 및 예방에 대한 관심으로 경도인지장애(mild cognitive impairment, $\mathrm{MCI}$ ) 환자의 언어 능력과 관련한 연구도 지속적으로 이루어 져 왔다. 지금까지 $\mathrm{MCI}$ 와 DAT 환자의 언어장애 연구는 대면이름 대기(Bayles \& Tomoeda, 1983; Chenery, Murdoch, \& Ingram, 1996; Lee, 2002; Martin \& Fedio, 1983), 범주유창성(Adlam, Bozeat, Arnold, Watson, \& Hodges, 2006)과 같은 의미적 측면에서의 언어 능
력을 평가하기 위한 과제가 가장 많이 사용되었다(Bayles, Tomoeda, Kaszniak, \& Trosset, 1991). 그러나 성인은 일상적인 의사소통 상황에서 내용이나 구조적으로 낱말이나 문장 이상의 보다 발전적 이고 복잡한 형태의 언어를 구사한다(Choi \& Choi, 2013). 따라서 성인을 대상으로는 실제 의사소통 상황에서의 효율성과 같은 보다 통합적 측면에서의 언어 평가 결과가 더 유용한 정보가 될 수 있다 (Nicholas \& Brookshire, 1993). 이러한 이유로 통합적인 언어 능력 에 대한 관심이 높아졌고, 담화(discourse) 과제를 통한 자발화 연 
구의 필요성이 대두되었다(Giles, Patterson, \& Hodges, 1996). MCI 와 DAT 환자를 대상으로도 다양한 담화 과제를 통한 자발화 산출 연구가 활발히 진행되어 왔고(Carlomagno, Santoro, Medditti, Pandolfi, \& Marini, 2005; Choi, 2011; Kim, Kim, Namkoong, Kim, \& $\mathrm{Kim}, 2006)$, 담화 산출 과제는 복합적인 언어 능력과 다양한 인지 과정을 포함하고 있기 때문에 MCI와 DAT 환자의 의사소통 능력 을 평가하는 데 임상적으로 유용하다는 것이 밝혀졌다(ForbesMckay \& Venneri, 2005; Giles et al., 1996). 담화 산출 과제 중 기존 의 연구에서 가장 사용 빈도가 높은 것은 설명적 담화의 한 유형인 그림설명 과제(picture description task)이다. MCI와 DAT 환자를 대상으로 한 그림설명 과제의 유용성에 대하여 Choi (2011)는 다음 과 같이 설명하였다. 첫째, 담화 산출 중 그림 자극이 지속적으로 제시되어 기억장애의 영향이 적고, 둘째, 분석 항목이 그림에 제시 되어 있기 때문에 다른 자발화 과제에 비해 분석이 용이하며, 비교 적 짧고 간단한 검사로 환자에게 부가되는 인지적, 심리적 부담이 적다. 또한, Lee와 Kim (2001)은 그림설명 과제는 여러 환자들에게 동일한 그림을 사용할 수 있어 객관적인 비교가 가능하다는 장점 을 가진다고 설명하였다.

신경언어장애 환자군을 대상으로 한 자발화 연구와 더불어 그들 의 언어 및 의사소통 능력을 평가하기 위한 자발화 분석 척도에 대 한 논의가 이루어졌고, 국내외 연구에서 다양한 분석 척도를 사용 한 연구가 진행되어 왔다. 특히, 의미적인 측면의 자발화 능력을 평 가하기 위한 분석 척도들이 가장 다양하게 사용되었다. 의미적 측 면의 자발화 분석 척도 중 가장 널리 사용되는 것은 Nicholas와 Brookshire (1993)에 의해 고안된 Correct Information Unit (CIU) 분석이다. CIU란 '문맥상 명료하고, 주제나 과제에 적합하며, 정확 한 정보를 제공하는 낱말'로 정의되며(Kwon, Kim, Choi, Na, \& Lee, 1998), 전체 발화에서 CIU가 차지하는 비율로 산출하는 'CIU 비율' 분석은 정보전달의 효율성을 평가하는 것으로 알려져 있다. 그러나 이러한 CIU 비율 분석의 경우 과제에 제시된 항목에 대한 발화 내용의 적절성만을 평가하기 때문에 자발화의 정보전달력이 나 효율성의 측면은 평가할 수 있지만, 과제의 핵심이 되는 정보를 포함하고 있는지, 대상자가 자발화 산출 과제의 주제나 요점을 파 악하고 있는지 평가하기는 어렵다는 한계가 있다(Nicholas \& Brookshire, 1995). 이러한 CIU 비율 분석 척도의 한계점을 보안하고자 Nicholas와 Brookshire (1995)는 주요개념(main concepts) 분석이 라는 자발화 분석 척도를 제시하였다. 주요개념 분석은 그림 상황 에 대한 필수 요소들의 포함 여부와 내용의 정확성 및 문장의 완전 성에 따라 대상자의 자발화를 분석하는 방법이다. 이러한 주요개 념 분석은 자발화 분석을 위한 일반적인 채점 기준을 마련하고 있
으며, 보스턴 실어증 검사(Boston Diagnostic Aphasia Examination, BDAE; Goodglass \& Kaplan, 1983) 항목에 포함된 Boston Cookie-Theft picture는 그림설명 과제로 널리 사용되고 있어 일부 의 연구에서 주요개념 분석 기준을 제시하고 있다(Groves-Wright, Neils-Strunjas, Burnett, \& O’Neill, 2004; Hier, Hagenlocker, \& Shindler, 1985). 이러한 주요개념 분석은 문법적 측면의 언어 손상 은 경미하지만, 의사소통 상황에서 핵심을 파악하고 전달하는 데 어려움이 있는 환자들의 자발화를 분석하는 데 효과적인 것으로 알려져 있다(Sohn, Kim, \& Park, 2007). 그러나 주요개념 분석은 주어진 과제에서 단어 수준의 핵심적인 내용의 포함 여부만을 평 가하기 때문에, 제한된 자발화 과제에서만 사용할 수 있으며, 전체 적인 정보전달 능력을 평가한다고 보기는 어렵다. 다음으로 대상자 가 산출한 한 발화에서 나타난 내용어의 평균 수로 자발화를 분석 하는 발화당 내용어수 분석도 일부 연구에서 사용되어 왔는데, 발 화당 내용어수 분석은 반복하여 사용한 내용어는 중복하여 계산 하지 않는 방식으로 분석한다(Kim et al., 2006; Lee \& Kim, 2001). 따라서 같은 양의 말을 산출하였어도 반복이나 간투사가 많거나, 기능어의 사용이 많은 대상자의 자발화 특성을 반영하기에 좋은 분석 척도로 알려져 있다. 그러나 발화당 내용어수 분석 척도는 내 용어의 산출 유무에만 초점이 맞춰져 있기 때문에 산출한 내용어 의 적절성을 판단하지는 않는다는 한계를 가진다.

국내 MCI와 DAT 환자들을 대상으로 한 자발화 산출 연구에서 는 CIU 비율 분석이 가장 빈도 높게 사용되었고(Choi, 2013; Jung, 2009; Sohn \& Park, 2008), 주요개념 분석(Choi, 2009; Sohn et al., 2007)과 발화당 내용어수 분석(Choi, 2011; Kim et al., 2006) 또한 사용되었다. 이러한 연구들은 $\mathrm{MCI}$ 및 DAT 환자의 기능적인 의사 소통 능력을 평가하는 데 각각의 자발화 분석 방법이 유용하다는 결과를 보여주고 있다. 그러나 MCI와 DAT 환자의 자발화 분석에 서 어떤 분석 척도를 사용하느냐가 연구 결과에 영향을 줄 수 있다 는 주장(Altmann, Kempler, \& Andersen, 2001)에도 불구하고 어 떠한 분석 척도가 $\mathrm{MCI}$ 와 DAT 환자들의 자발화 능력을 잘 반영하 는지 비교 분석한 연구는 찾아보기 어렵다. 따라서 본 연구는 일반 고령자, $\mathrm{MCI}, \mathrm{DAT}$ 환자를 대상으로 기존 자발화 연구에서 사용 빈도가 높은 CIU 비율(낱말과 어절), 주요개념, 발화당 내용어수 분석 척도로 동일한 자발화 자료를 분석하여 집단 간의 차이를 비 교하는 것을 목적으로 하였다. 또한, ROC 곡선 분석을 통하여 각 집단 간 민감도와 특이도 측면에서 변별도가 높은 분석 척도를 알 아보고, 그 결과를 통해 자발화 분석 척도의 유용성을 평가하고자 하였다. 


\section{연구 방법}

\section{연구 대상}

본 연구에 참여한 대상자는 한국어를 모국어로 사용하는 일반 고령자 30 명, $\mathrm{MCI}$ 환자 30 명, $\mathrm{DAT}$ 환자 30 명으로 총 90 명이었다. 일 반 고령자는 수도권과 충청 지역에 거주하는 노인을 대상으로 하였 고, $\mathrm{MCI}$ 와 DAT 환자는 정신과 전문의에 의해 진단된 경우로 국한 하였다. 모든 집단은 남성 15 명, 여성 15 명으로 성비를 통제하였다.

우선 일반 고령자는 (1) 한국판 간이정신상태검사(Korean MiniMental State Examination, K-MMSE; Kang, 2006) 점수가 연령과 교육 연수의 규준과 비교하여 -1.0 SD 이상으로, (2) 인지기능에 영 향을 줄 수 있는 신경학적 질환의 경험이 없으며, (3) 과제를 수행하 는 데 필요한 지시 따르기 및 시청각 능력을 보유한 대상자로 하였다.

다음으로 MCI 환자는 Petersen 등(2001)의 진단 기준에 따라 정 신과 전문의에게 기억상실형 $\mathrm{MCI}$ (amnestic $\mathrm{MCI}, \mathrm{aMCI}$ 로 진단 받은 환자로 (1) 주관적인 기억장애를 호소하고, (2) K-MMSE 점수 가 정상 범주에 속하며, (3) Barthel Index (Mahoney, 1965) 점수가 20점으로 일상생활 활동(activities of daily living) 능력이 정상으 로, (4) Korean version of the Consortium to Establish a Registry for Alzheimer's Disease Assessment Packet (CERAD-K; Lee et al., 2002)의 단어목록회상, 단어목록재인, 구성회상 중 하나 이상의 수 행이 -1.5 SD 이하로 객관적 기억력 손상이 나타나며, (5) 치매의 진 단 기준에 부합하지 않는 대상자로 하였다. 연구 대상이 된 $\mathrm{MCI}$ 환 자는 Clinical Dementia Rating (CDR; Morris, 1993)의 총 점수가 모두 0.5였으며, 단일영역(single domain) aMCI와 다발영역(multiple domains) aMCI가 포함되었다.

다음으로 DAT 환자는 Diagnostic and Statistical Manual of Mental Disorders, fourth edition (DSM-IV; American Psychiatric Association, 1994)의 진단 기준과 뇌영상 소견에 의해 정신과 전문의 에 의해 $\mathrm{DAT}$ 로 진단받고, $\mathrm{CDR}$ 의 총 점수가 .5 또는 1 인 아주 초기 (very early)와 초기(early)의 환자로 한정하였다.

각 집단의 연령 및 교육 연수, K-MMSE 점수의 기술 통계치를 Table 1에 제시하였다. 또한, 연령, 교육 연수, K-MMSE 점수에 집단 간 차이가 있는지 알아보기 위하여 일원배치분산분석을 실시하였 다. 분석 결과, 연령 $(F=2.482, p>.05)$ 과 교육 연수 $(F=2.894, p>.05)$ 에서는 집단 간 차이가 유의하지 않았고, $\mathrm{K}-\mathrm{MMSE}$ 점수 $(F=35.182$, $p<.05)$ 에서만 집단 간 차이가 유의하였다. K-MMSE 점수의 사후 분석 결과 일반 고령자와 $\mathrm{MCI}$ 집단 간에는 유의한 차이가 없었지 만, 일반 고령자와 $\mathrm{MCI}$ 집단은 경도 DAT 집단에 비해 K-MMSE 점 수가 유의하게 높은 것으로 나타났다.
Table 1. Results for age, education level, and K-MMSE score by group

\begin{tabular}{lccc}
\hline & Age $(y r)$ & Education $(y r)$ & K-MMSE \\
\hline NC $(\mathrm{N}=30)$ & $72.53(4.09)$ & $9.26(3.26)$ & $27.03(1.69)$ \\
MCl $(\mathrm{N}=30)$ & $71.43(3.87)$ & $9.13(3.78)$ & $26.10(1.60)$ \\
DAT $(\mathrm{N}=30)$ & $73.93(4.22)$ & $7.23(3.90)$ & $22.73(2.76)$ \\
\hline
\end{tabular}

Values are presented as mean (SD).

K-MMSE = Korean version of Mini-Mental Status Examination (Kang, 2006); NC= normal cognition; $\mathrm{MCl}=$ mild cognitive impairment; $\mathrm{DAT}=$ dementia of Alzheimer's type.

\section{연구 과제 및 연구 절차}

본 연구에서는 그림설명 과제로 BDAE (Goodglass \& Kaplan, 1983)에 포함된 Boston Cookie-Theft picture를 사용하였다. Boston Cookie-Theft picture는 널리 사용되는 그림설명 과제로 다른 실어증 검사에 포함된 그림에 비해 이야기에 기반한 응집력 있는 (cohesive) 발화 내용을 얻을 수 있는 것으로 알려져 있다(Correia, Brookshire, \& Nicholas, 1990). 또한 MCI 및 DAT 환자의 자발화 능력을 평가하는 데 타당하다고 알려져 있으며(Giles et al., 1996), 국내 연구에서도 뇌손상 환자들의 자발화를 평가하기 위해 많이 사용되고 있다(Choi, 2011; Im, Kwon, \& Sim, 2001).

모든 검사는 조용한 장소에서 개별적으로 실시하였다. 대상자에 게 과제에 대해 간단히 소개한 후 A4용지 크기의 그림을 제시하고 “이 그림을 보고 저에게 자세히 설명해 주세요."라고 지시하여 반 응을 유도하였다. 대상자가 반응하는 동안에 검사자는 어떠한 개 입도 하지 않았으며, 대상자의 발화가 끝나면 "더 하실 이야기가 있 으면 해 주세요.”라고 발화의 기회를 한 번 더 제공하였다. 대상자 들의 발화는 시간 제한을 두지 않았으며, PCM recording R4를 사 용하여 녹음하고 즉시 전사하였다. 기존의 연구(Kwon et al., 1998) 에 근거하여 30 초 이상의 연속 발화만 분석에 사용하였다.

\section{자료 분석}

본 연구에서 사용한 자발화 분석 척도는 CIU 낱말(CIU-morphological word)과 CIU 어절(CIU-syntactic word) 비율, 주요개념 분석, 발화당 내용어수였다. 우선, CIU 낱말과 어절 비율은 Nicholas와 Brookshire (1993)의 분석 지침을 기준으로 대상자가 산출한 낱말이나 어절 중 명료하고, 과제에 적합하며, 정확한 정보를 전달 하는 낱말이나 어절이 차지하는 비율로 산출하였다. 어절 및 낱말 분석 지침은 Yi (2015)를 따랐다. 다음으로 주요개념 분석은 Hier 등(1985)의 주요개념 분석 체계를 일부 수정한 Choi (2009)의 연구 를 따랐으며, 구체적인 분석 기준을 Appendix 1에 제시하였다. 마 지막으로 발화당 내용어수 분석은 내용어의 총합을 총발화 수로 나누어 계산하였다. 발화 구분은 Kim, Yoon, Kim, Chang과 Cha 
(2012)의 기준을 따랐으며, 한 발화 내에서 반복하여 사용한 내용 어는 중복하여 계산하지 않았다. Yi (2015)의 기준에 따라 내용어 에는 명사, 수사 등의 체언, 동사, 형용사 등의 용언, 관형사, 부사 등 의 수식언을 포함시키고, 기능어의 특징이 뚜렷한 접속 부사, 조사, 보조용언과 의존명사는 제외하였다. 단, 대명사는 내용어에 포함시 키지 않았다. 각 분석 척도의 산출 공식은 Table 2에 제시하였다.

\section{신뢰도}

신뢰도는 제 2 평가자와의 평가자 간 신뢰도(inter-rater reliability) 로 측정하였다. 제 1 평가자는 연구자이며, 제 2 평가자는 언어병리학 석사학위 소지자로 임상경력 3 년 이상의 언어재활사였다. 제 2 평가 자는 연구 내용을 잘 알고 있으며, 분석 척도별 채점기준을 신뢰도 산출 이전에 충분히 숙지하도록 하였다. 신뢰도 평가는 전체 자료 의 $13 \%$ 에 해당하는 집단별 각 4 명씩 총 12 명의 녹음자료를 무작위 로 선정하여 두 평가자가 독립적으로 분석 후 일치도를 산출하였 다. 분석 결과, 각 분석 척도별 평가자 간 일치도는 CIU 어절 비율은 $92.7 \%, \mathrm{CIU}$ 낱말 비율은 $91.6 \%$, 주요개념은 $94.4 \%$, 발화당 내용어 수는 $90.4 \%$ 로 나타났다.

\section{통계처리}

통계 분석은 IBM SPSS Statistics ver. 22 프로그램을 사용하였다. 우선 수집된 자발화 수행 자료의 정규성을 확인하기 위해 ShapiroWilk 검정을 실시한 결과 정규성을 충족하지 않아 자발화 분석 척 도에 따른 그림설명 과제 수행의 집단 간 차이를 알아보기 위하여 Kruskal-Wallis 검정을 실시하고, 집단 간 차이가 유의한 경우 Mann-Whitney U 검정을 통해 사후 검정을 실시하였다. 다음으로 집단에 따른 자발화 분석 척도의 변별도를 확인하기 위하여 민감 도(sensitivity) 및 특이도(specificity)를 통한 ROC 곡선 분석을 실

Table 3. Results of the spontaneous speech analysis scales for picture description task

\begin{tabular}{lcccc}
\hline Group & $\begin{array}{c}\text { Ratio of CIU- } \\
\text { morphological } \\
\text { words (\%) }\end{array}$ & $\begin{array}{c}\text { Ratio of } \\
\text { CIU-syntactic } \\
\text { words (\%) }\end{array}$ & $\begin{array}{c}\text { Main } \\
\text { concepts }\end{array}$ & $\begin{array}{c}\text { Number of } \\
\text { content words } \\
\text { by utterance }\end{array}$ \\
\hline NC & $79.47(17.33)$ & $80.01(17.13)$ & $4.36(2.07)$ & $4.91(1.24)$ \\
MCI & $71.67(20.56)$ & $72.32(20.78)$ & $3.73(1.72)$ & $4.28(1.42)$ \\
DAT & $60.98(21.53)$ & $61.49(22.36)$ & $2.93(2.01)$ & $3.96(1.27)$ \\
\hline
\end{tabular}

$\mathrm{CIU}=$ Correct Information Unit; $\mathrm{NC}=$ normal cognition; $\mathrm{MCl}=$ mild cognitive impairment; DAT = dementia of Alzheimer's type.

Table 2. Calculation formula of spontaneous speech analysis scales

\begin{tabular}{lc}
\hline Analysis scale & Calculation formula \\
\hline Ratio of CIU-morphological words (\%) & $\frac{\text { Number of CIU-morphological word }}{\text { Total number of morphological words }} \times 100$ \\
Ratio of CIU-syntactic words (\%) & $\frac{\text { Number of CIU-syntactic word }}{\text { Total number of syntactic words }} \times 100$ \\
Main concepts & Given one score for each utterance of main concept (maximum score 8) \\
Number of content words by utterance & $\frac{\text { Number of content words }}{\text { Total number of utterances }}$ \\
\hline
\end{tabular}

$\mathrm{CIU}=$ Correct Information Unit.

Table 4. Results of the spontaneous speech analysis scales of Kruskal-Wallis and Mann-Whitney U-test for three groups

\begin{tabular}{|c|c|c|c|c|}
\hline Scale & Group & Mean rank & $x^{2}$ & Group comparison \\
\hline Ratio of CIU- morphological words & $\begin{array}{l}\mathrm{NC} \\
\mathrm{MCl} \\
\mathrm{DAT}\end{array}$ & $\begin{array}{l}56.25 \\
46.87 \\
33.38\end{array}$ & $11.622^{* *}$ & $\begin{array}{l}\text { NC vs. MCl: NS } \\
\text { MCI vs. DAT: NS } \\
\text { NC> DAT: S }\end{array}$ \\
\hline Ratio of CIU-syntactic words & $\begin{array}{l}\mathrm{NC} \\
\mathrm{MCl} \\
\mathrm{DAT}\end{array}$ & $\begin{array}{l}56.50 \\
46.67 \\
33.33\end{array}$ & $11.890^{* *}$ & $\begin{array}{l}\text { NC vs. MCl: NS } \\
\mathrm{MCl}>\text { DAT: } S \\
\mathrm{NC}>\text { DAT: } S\end{array}$ \\
\hline Main concepts & $\begin{array}{l}\mathrm{NC} \\
\mathrm{MCL} \\
\mathrm{DAT}\end{array}$ & $\begin{array}{l}53.85 \\
46.50 \\
36.15\end{array}$ & $7.105^{*}$ & $\begin{array}{l}\text { NC vs. MCl: NS } \\
\text { MCI vs. DAT: NS } \\
\text { NC>DAT: S }\end{array}$ \\
\hline Number of content words by utterance & $\begin{array}{l}\mathrm{NC} \\
\mathrm{MCl} \\
\mathrm{DAT}\end{array}$ & $\begin{array}{l}58.40 \\
41.33 \\
36.77\end{array}$ & $11.438^{* *}$ & $\begin{array}{l}\mathrm{NC}>\mathrm{MCl}: \mathrm{S} \\
\mathrm{MCl} \text { vs.DAT: NS } \\
\mathrm{NC}>\mathrm{DAT}: \mathrm{S}\end{array}$ \\
\hline
\end{tabular}

$\mathrm{CIU}=$ Correct Information Unit; $\mathrm{NC}=$ normal cognition; $\mathrm{MCl}=$ mild cognitive impairment; $\mathrm{DAT}=$ dementia of Alzheimers type; NS= not significant; $\mathrm{S}=$ significant. ${ }^{*} p<.05,{ }^{* *} p<.01$. 
시하였고, 각 집단을 변별하는 데 유의한 것으로 나타난 자발화 분 석 척도에 대하여 절단점(cut-off score), 민감도, 특이도 및 진단정 확도를 산출하였다.

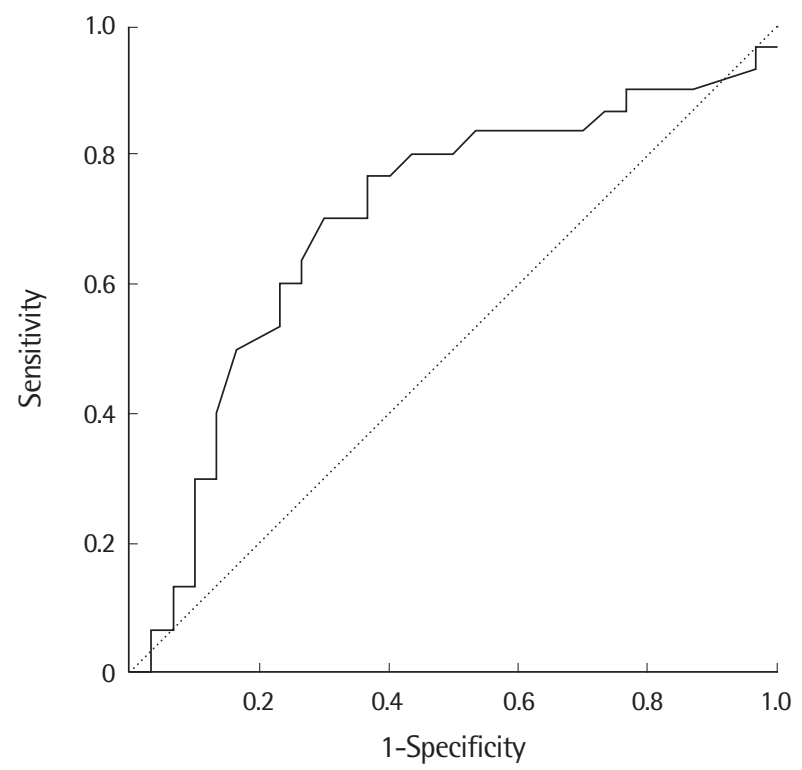

Figure 1. ROC curve of the number of content words by utterance scale for normal cognition (NC) and mild cognitive impairment (MCl) groups.

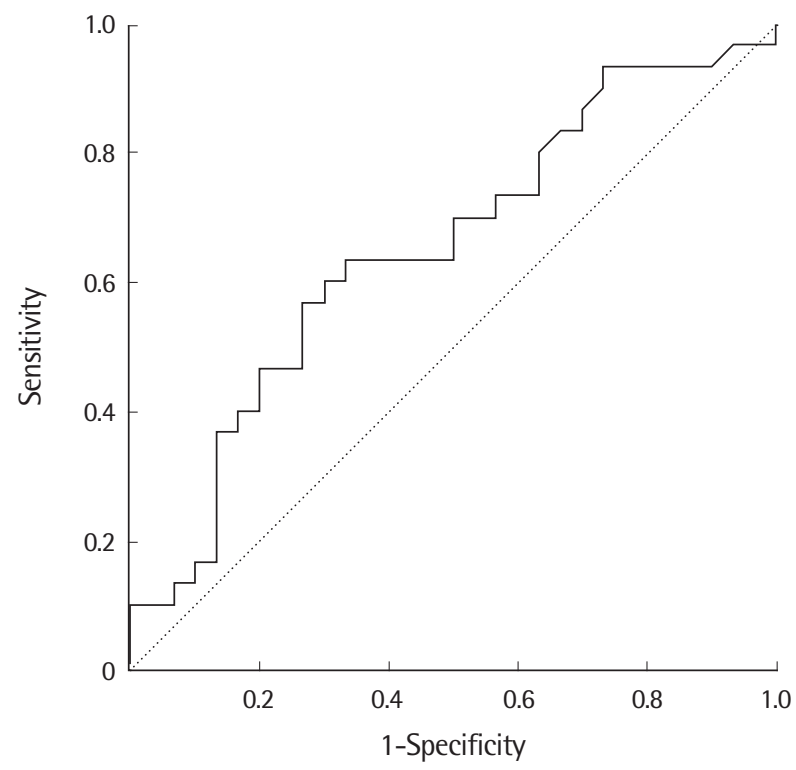

Figure 2. ROC curve of the ratio of CIU-syntactic words scale for mild cognitive impairment (MCI) and dementia of Alzheimer's type (DAT) groups. CIU= Correct Information Unit.

\section{연구 결과}

\section{자발화 분석 척도에 따른 집단 간 그림설명 과제의 수행 차이}

$\mathrm{CIU}$ 낱말 비율, $\mathrm{CIU}$ 어절 비율, 주요개념, 발화당 내용어수 분석 을 통한 일반 고령자, MCI, DAT 집단의 그림설명 과제 수행에 대한 평균 및 표준편차를 Table 3에, Kruskal-Wallis 검정과 Mann-Whitney U 검정을 통한 사후 검정 결과를 Table 4에 제시하였다. 결과를 살펴보면, 네 가지 분석 척도 모두 집단 간 차이가 유의한 것으로 나 타났다. 집단 간 비교 결과 일반 고령자 집단은 $\mathrm{MCI}$ 집단에서 비해 발화당 내용어수 분석에서만, MCI 집단은 경도 DAT 집단에 비해 $\mathrm{CIU}$ 어절 비율 분석 척도에서만 유의하게 수행이 높았다. 마지막으 로 일반 고령자 집단은 DAT 집단에 비해 네 가지 분석 척도 모두에 서 유의하게 수행이 높은 것으로 나타났다.

\section{$\mathrm{ROC}$ 곡선을 통해 살펴본 자발화 분석 척도의 유용성}

집단 간 비교 결과 유의하게 차이를 보였던 각각의 자발화 분석 척도의 유용성을 평가하기 위하여 ROC 곡선 분석을 실시하였다. 일반 고령자와 $\mathrm{MCI}$ 집단의 발화당 내용어수 분석 척도의 ROC 곡 선을 Figure 1에, $\mathrm{MCI}$ 와 DAT 집단의 $\mathrm{CIU}$ 어절 비율 분석 척도의 ROC 곡선을 Figure 2에, 마지막으로 일반 고령자와 DAT 집단의 네 가지 분석 척도의 ROC 곡선을 Figure 3에 제시하였다.

집단별 그림설명 과제의 수행 차이가 유의하게 나타난 자발화 분

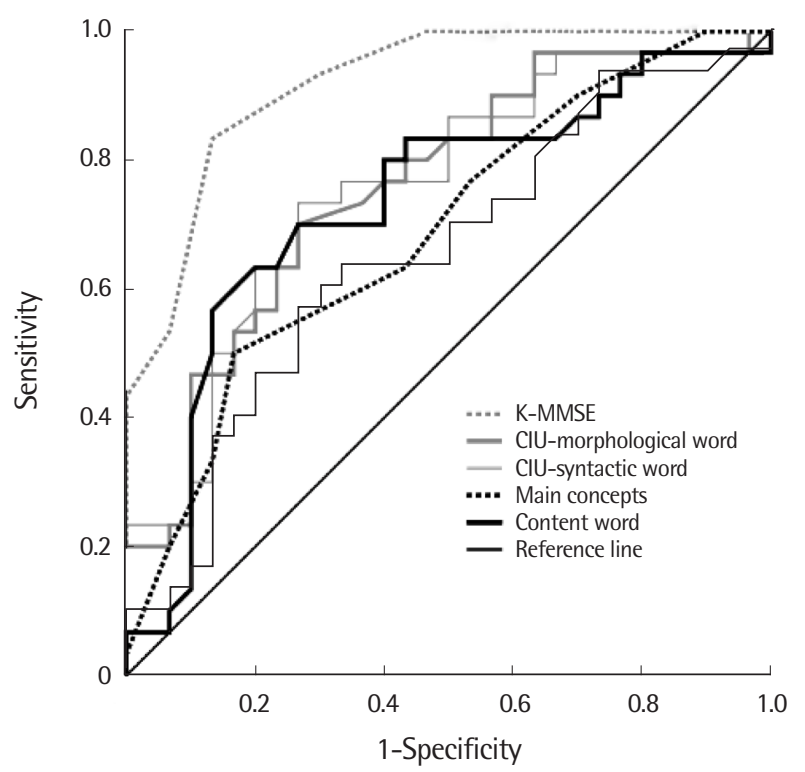

Figure 3. ROC curve of the spontaneous speech analysis scales for normal cognition (NC) and dementia of Alzheimer's type (DAT) groups. K-MMSE=Korean version of Mini-Mental Status Examination; CIU=Correct Information Unit. 
Table 5. Results on analysis of the spontaneous speech in three groups by ROC curve

\begin{tabular}{|c|c|c|c|c|c|c|}
\hline Group comparison & Scale & AUC & Cut-off value & Sensitivity (\%) & Specificity (\%) & Validity (\%) \\
\hline NC vs. MCl & Number of content words by utterance & $.697^{* *}$ & 4.9 & 73.3 & 63.3 & 68.3 \\
\hline MCl vs. DAT & Ratio of CIU-syntactic words & $.649^{*}$ & $71.8^{\mathrm{a}}$ & 50.0 & 70.0 & 60.0 \\
\hline NC vs. DAT & $\begin{array}{l}\text { Ratio of CIU-morphological words } \\
\text { Ratio of CIU-syntactic words } \\
\text { Main concepts } \\
\text { Number of content words by utterance }\end{array}$ & $\begin{array}{l}.757^{* *} \\
.756^{* *} \\
.689^{*} \\
.733^{* *}\end{array}$ & $\begin{array}{c}75.2^{\mathrm{a}} \\
74.2^{\mathrm{a}} \\
4.5 \\
4.8\end{array}$ & $\begin{array}{l}56.7 \\
60.0 \\
56.7 \\
73.3\end{array}$ & $\begin{array}{l}80.0 \\
76.7 \\
63.3 \\
70.0\end{array}$ & $\begin{array}{l}68.3 \\
68.3 \\
60.0 \\
71.7\end{array}$ \\
\hline
\end{tabular}

$\mathrm{AUC}=$ area under curve; $\mathrm{NC}=$ normal cognition; $\mathrm{MCl}=$ mild cognitive impairment; $\mathrm{DAT}=$ dementia of Alzheimer's type; $\mathrm{CIU}=$ Correct Information Unit.

${ }^{a}$ Calculated as a percentage.

${ }^{*} p<.05,{ }^{* *} p<.01$.

석 척도들에 대하여 ROC 곡선 분석을 실시하고, 집단에 따른 자발 화 분석 척도의 ROC 면적률, 절사치, 민감도, 특이도 및 진단정확 도를 Table 5에 제시하였다. 분석 결과, 모든 분석 척도가 민감도와 특이도 측면에서 통계적으로 유의한 것으로 나타났다. 일반 고령자 와 DAT 환자의 경우에는 ROC 면적률 기준으로 CIU 낱말 비율, $\mathrm{CIU}$ 어절 비율, 발화당 내용어수, 주요개념 분석 척도 순으로 변별 도가 높은 것으로 나타났다.

\section{논의 및 결론}

본 연구의 첫 번째 연구 목적은 일반 고령자, $\mathrm{MCI}, \mathrm{DAT}$ 환자를 대상으로 기존 자발화 연구에서 사용 빈도가 높은 자발화 분석 척 도로 동일한 자발화 자료를 분석하여 집단 간의 차이를 비교하는 것이었다. 결과를 살펴보면 우선 일반 고령자와 $\mathrm{MCI}$ 집단의 경우 발화당 내용어수 분석에서만 수행 차이가 유의한 것으로 나타났 다. 이러한 결과는 일반 고령자와 치매의심 집단 간 발화당 내용어 수에서 통계적으로 유의한 차이를 보고한 Kim 등(2006)의 선행연 구 결과와 일치한다. 본 연구에서 나타난 일반 고령자와 $\mathrm{MCI}$ 환자 집단의 발화당 내용어수의 차이가 어떤 차이에서 기인하는지 알아 보기 위하여 추가적으로 자발화에서 나타난 총 낱말 수와 평균낱 말길이(MLU-w)를 분석한 결과 산출한 총 낱말수와 평균낱말길이 는 두 집단 간 차이가 유의하지 않은 것으로 나타났다. 즉, 두 집단 간 발화당 내용어수 분석에서의 차이는 $\mathrm{MCI}$ 환자들의 동일한 내 용어의 반복, 간투사나 기능어 등의 삽입으로 인한 것임을 유추해 볼 수 있다. 이러한 결과는 기존 연구와 일치하는 측면이 있는데 $\operatorname{Kim}$ 등(2006)은 치매 의심군이 일반 고령자군에 비해 상대적으로 간투사나 기능어를 더 많이 사용하였다고 보고하고 있고, Choi (2011)는 MCI 집단이 일반 고령자 집단에 비해 그림설명 과제에서 동일한 내용어를 많이 반복하여 사용했음을 보고하였다. 기존의 연구에서 이러한 MCI 환자들의 발화당 내용어수의 저하는 낱말 인출(word retrieval) 능력의 제한과 관련하여 설명하고 있다(Ap- pell, Kertesz, \& Fisman, 1982). 즉, 그림설명 과제에서 MCI 환자들 은 낱말 인출 시간이 지연되어 일반 고령자에 비해 낱말 반복이나 간투사를 많이 산출하고, 대명사를 더 많이 사용한 것으로 해석할 수있다.

다음으로 일반 고령자와 $\mathrm{MCI}$ 집단 간에 CIU 낱말 및 어절 비율 과 주요개념 분석에서는 유의한 차이가 없는 것으로 나타났는데, 이는 선행연구의 결과와 다소 일치하지 않는다. Kim 등(2006)은 그 림설명 과제 수행에서 일반 고령자 집단에 비해 치매의심 집단이 $\mathrm{CIU}$ 낱말 비율에서 유의미하게 수행이 낮은 것으로 보고하였고, Choi, Kim, Lee와 Kim (2013)도 CIU 어절 비율에서 일반 고령자와 $\mathrm{MCI}$ 집단 간 차이가 유의하였다고 보고하였다. 주요개념 분석에서 도 Choi (2009)는 일반 고령자와 MCI 집단 간에 유의한 차이를 보 였다고 보고하고 있다. 이렇듯 기존 연구 결과와 본 연구 결과가 일 치하지 않는 이유는 연구 대상이 된 MCI 환자 집단의차이 때문으로 생각해 볼 수 있다. Petersen (2004)은 MCI가 정상적인 노화와 매 우 초기의 치매단계 사이에 존재한다는 인지적 연속선 개념(cognitive continuum)을 제시하였다. 따라서 MCI 안에는 정상적인 노화 에 가까운 인지 능력을 소유한 집단이 있는 반면, 치매상태 직전의 집단도 존재하게 된다. 이러한 $\mathrm{MCI}$ 집단의 이질성과 관련하여 최 근 O'Bryant 등(2010)은 CDR 박스총점(CDR sum of boxes, CDR$\mathrm{SB}$ )을 기준으로 $\mathrm{MCI}$ 환자를 $\mathrm{MCI}$ 와 ‘매우 경한 치매'로 구분하는 것이 필요하다고 제안하기도 하였다. 이렇듯 $\mathrm{MCI}$ 집단에는 다양한 인지기능을 가진 $\mathrm{MCI}$ 가 혼재하기 때문에 어떤 MCI 대상자들이 포함되었는가에 따라 연구 결과에 영향을 미칠 수 있다. 실제로 본 연구의 결과와 상이한 결과를 보였던 기존의 Kim 등(2006)이나 Choi 등(2013)의 연구에 포함된 MCI 대상자들은 일반 고령자 집단 에 비해 K-MMSE 점수가 유의하게 낮았다. 반면, 본 연구의 MCI 대 상자들은 일반 고령자 집단과 K-MMSE에서 유의한 차이를 보이지 않아 일반 고령자에 더 가까운 $\mathrm{MCI}$ 라고 판단할 수 있다. 이와 관련 하여 Choi (2011)의 연구에서 K-MMSE와 CIU 비율의 상관을 살펴 보았는데 그 결과 유의한 정적상관이 나타났다. 이는 인지기능이 의 
미적 측면의 언어장애와 관련이 있음을 시사한다. 따라서 본 연구 의 대상자들은 비록 $\mathrm{MCI}$ 로 진단받은 환자들이지만, 아직 초기의 환자들로 정보전달 능력 및 자발화의 핵심 내용을 설명하는 능력 이 상대적으로 양호한 것으로 해석할 수 있다. 이러한 결과는 MCI 환자들을 대상으로 한 연구의 대상자 선정 단계에서 $\mathrm{MCI}$ 환자들 을 좀 더 세분화하여 면밀하게 살펴 볼 필요성이 있음을 시사한다.

두 번째로 네 가지 자발화 분석 척도를 사용하여 그림설명 과제 를 통한 $\mathrm{MCI}$ 집단과 $\mathrm{DAT}$ 집단의 자발화를 분석한 결과 $\mathrm{MCI}$ 집단 은 DAT 집단에 비해 CIU 어절 비율에서만 유의하게 수행이 높은 것으로 나타났다. 이러한 결과는 기존의 연구 결과(Choi et al., 2013) 와 일치하는데, 이는 DAT 환자들이 $\mathrm{MCI}$ 환자들에 비해 적절하게 정보를 전달하는 능력이 부족하고, 그림의 내용과 관계없는 발화 를 많이 산출하기 때문인 것으로 여겨진다. 따라서 산출된 내용의 적절성을 평가하는 $\mathrm{CIU}$ 어절 비율 분석 척도가 DAT 환자의 자발 화 손상을 민감하게 반영하는 것으로 해석할 수 있다. 그러나 동일 하게 정보전달의 효율성을 평가하는 CIU 어절과 CIU 낱말 비율 분석 척도 간 기술통계 상으로는 큰 차이가 없었지만, 유의수준.05 에서 $\mathrm{CIU}$ 어절 비율에서는 두 집단 간 차이가 유의하였고, $\mathrm{CIU}$ 낱 말 비율에서는 두 집단 간 차이가 유의하지 않았다. 이러한 CIU 어 절과 CIU 낱말 비율 분석 척도 간의 상이한 결과는 두 CIU 비율 분석 척도를 구성하는 요인의 차이로 설명할 수 있다. CIU 어절 비 율은 의미론적 관점의 평가에 초점을 두고 있는 반면, CIU 낱말 비 율은 의미론적인 요소와 함께 조사와 같은 문법적인 요소들의 사 용 능력을 평가하고 있다. DAT 환자들의 언어 능력은 의미적 측면 에 비해 상대적으로 형태나 구문론적 능력이 보존되어 있는 것으 로 알려져 있다(Appell et al., 1982; Bayles, Kaszniak, \& Tomoeda, 1987; Jung, 2009; Kempler, Curtiss, \& Jackson, 1987). 따라서 의미 적인 측면만을 반영한 $\mathrm{CIU}$ 어절 비율이 DAT 환자의 언어 손상을 더 민감하게 검출할 수 있었던 것으로 보인다.

다음으로 MCI와 DAT 집단 간 발화당 내용어수와 주요개념 분 석에서는 유의한 차이를 보이지 않는 것으로 나타났다. 이와 같은 결과는 $\mathrm{MCI}$ 와 경도 DAT 집단 간에 발화당 내용어수에서 유의한 차이를 보이지 않았다고 보고된 연구(Kim et al., 2006)와주요개념 점수가 $\mathrm{MCI}$ 와 $\mathrm{DAT}$ 집단 간 유의한 차이를 보이지 않았다고 보고 한 기존 연구(Choi, 2009)와 일치하는 결과라 할 수 있다. 발화당 내 용어수는 내용어의 산출유무에만 초점을 맞출 뿐 대상자가 산출 한 내용어가 제시된 그림 상황에 적절하고 정확한지는 알 수 없다. 즉, $\mathrm{MCI}$ 와 DAT 집단이 산출한 내용어의 개수는 유사하더라도 두 집단이 산출한 내용어가 과제에 적절한 내용어인지 아닌지는 구분 할 수 없다. 주요개념 분석 척도 역시 담화를 통합적으로 평가하기
보다는 단어 수준의 핵심적 내용의 포함유무만을 평가하기 때문 에 대상자가 담화의 전체적인 맥락이나 주제를 파악하고 있는지를 평가하기는 어렵다. 이러한 이유로 발화당 내용어수 및 주요개념 분석으로는 $\mathrm{CIU}$ 비율에서 검출되었던 $\mathrm{MCI}$ 와 DAT 집단의 자발 화 능력 차이가 드러나지 않는 것으로 여겨진다.

세 번째로 네 가지 자발화 분석 척도를 사용하여 그림설명 과제 를 통한 일반 고령자와DAT 집단의 자발화를 분석한 결과, 일반 고 령자 집단은 DAT 집단에 비해 모든 분석 척도에서 유의하게 수행 이 높은 것으로 나타났다. DAT 집단은 이미 $\mathrm{MCI}$ 를 넘어 일상생활 수행 능력의 저하가 나타나고, 그와 함께 일상적인 의사소통 능력 의 저하를 보이는 집단이다. 따라서 일반 고령자와 DAT 집단 간의 현격한 자발화 능력의 차이로 인해 모든 분석 척도에서 유의한 차 이를 보인 것으로 여겨진다. 이러한 결과는 네 가지 분석 척도 모두 정상적인 노화로 인한 자발화 능력의 제한과 DAT로 인한 병리적 인 자발화 능력의 변화를 구분해 낼 수 있음을 시사한다.

이 연구의 두 번째 연구 목적은 ROC 곡선 분석으로 일반 고령자 와 $\mathrm{MCI}, \mathrm{DAT}$ 집단 간 민감도와 특이도 측면에서 변별도가 높은 자 발화 분석 척도를 파악하고, 이러한 결과를 통해 자발화 분석 척도 의 유용성을 알아보는 것이었다. 분석 결과 집단 간 유의한 차이를 보인 모든 자발화분석 척도의 변별도가 유의하였다. 즉, 일반 고령자 와 $\mathrm{MCI}$ 환자를 변별하기 위해서는 발화당 내용어수 분석이, $\mathrm{MCI}$ 와 DAT 환자를 변별하기 위해서는 CIU 어절 비율이 민감도와 특 이도 측면에서 유의한 변별도를 지닌 것으로 나타났다. 일반 고령 자와 DAT 집단 간에는 네 가지 분석 척도 모두 변별도가 유의하게 높았으며, 진단정확도의 측면에서는 CIU 낱말 비율, $\mathrm{CIU}$ 어절 비 율, 발화당 내용어수, 주요개념 순으로 변별도가 높았다. 이러한 결 과는 $\mathrm{MCI}$ 환자에게는 발화당 내용어수 분석이, DAT 환자에게는 $\mathrm{CIU}$ 어절 비율로 자발화를 분석하는 것이 이들의 언어 능력의 변 화를 가장 민감하고 정확하게 평가할 수 있음을 시사한다.

$\mathrm{MCI}$ 와 DAT의 진단은 다양한 신경심리검사를 포함한 진단기준 에 부합하여 이루어지지만 본 연구의 결과는 자발화 평가가 이러 한 환자들을 통계적으로 유의하게 변별할 수 있을 만큼 이들의 언 어 능력 차이를 민감하게 반영할 수 있음을 시사한다. 특히, 정상적 인 노화, MCI, DAT로 진행하는 과정에서 이들의 언어 능력의 변화 를 민감히 검출해낼 수 있는 자발화 분석 척도가 서로 상이함을 확 인했다는 점이 본 연구의 가장 주요한 임상적인 의의로 생각할 수 있다. 다만, 그림설명 과제 이외의 다양한 담화 산출 과제를 사용하 지 못한 점이 아쉬움으로 남는다. 앞으로는 보다 다양한 담화 산출 과제를 사용하여 $\mathrm{MCI}$ 와 DAT환자의 자발화 분석 척도의 유용성 을 평가하는 후속연구가 진행되기를 바란다. 


\section{REFERENCES}

Adlam, A. L. R., Bozeat, S., Arnold, R., Watson, P., \& Hodges, J. R. (2006). Semantic knowledge in mild cognitive impairment and mild Alzheimer's disease. Cortex, 42, 675-684.

Altmann, L. J., Kempler, D., \& Andersen, E. S. (2001). Speech errors in Alzheimer's disease: reevaluating morphosyntactic preservation. Journal of Speech, Language, and Hearing Research, 44, 1069-1082.

American Psychiatric Association. (1994). Diagnostic and Statistical Manual of Mental Disorders 4th edition (DSM-IV). Washington, DC: Author.

Appell, J., Kertesz, A., \& Fisman, M. (1982). A study of language functioning in Alzheimer patients. Brain and Language, 17, 73-91.

Bayles, K. A., \& Tomoeda, C. K. (1983). Confrontation naming impairment in dementia. Brain and Language, 19, 98-114.

Bayles, K. A., Kaszniak, A. W., \& Tomoeda, C. K. (1987). Communication and cognition in normal aging and dementia. Boston, MA: College-Hill Press.

Bayles, K. A., Tomoeda, C. K., Kaszniak, A. W., \& Trosset, M. W. (1991). Alzheimer's disease effects on semantic memory: loss of structure or impaired processing? Journal of Cognitive Neuroscience, 3, 166-182.

Carlomagno, S., Santoro, A., Menditti, A., Pandolfi, M., \& Marini, A. (2005). Referential communication in Alzheimer's type dementia. Cortex, 41, 520534.

Chenery, H. J., Murdoch, B. E., \& Ingram, J. C. (1996). An investigation of confrontation naming performance in Alzheimer's dementia as a function of disease severity. Aphasiology, 10, 423-441.

Choi, C. S., \& Choi, H. (2013). Story comprehension ability in patients with MCI and DAT. Journal of Speech-Language and Hearing Disorders, 22, 159180.

Choi, H. (2009). Performances in a picture description task in Japanese patients with Alzheimer's disease and with mild cognitive impairment. Korean Journal of Communication Disorders, 14, 326-337.

Choi, H. (2011). Detecting language deficits in patients with mild cognitive impairment through verbal fluency and picture description tasks. Korean Journal of Communication Disorders, 16, 171-184.

Choi, H. (2013). Characteristics of naming and discourse in patients with amnestic mild cognitive impairment. Journal of Speech-Language and Hearing Disorders, 22, 17-33.

Choi, H., Kim, J. H., Lee, C. M., \& Kim, J. I. (2013). Features of semantic language impairment in patients with amnestic mild cognitive impairment.
Dementia and Neurocognitive Disorders, 12, 33-40.

Correia, L., Brookshire, R. H., \& Nicholas, L. E. (1990). Aphasic and nonbrain-damaged adults' descriptions of aphasia test pictures and gender-biased pictures. Journal of Speech and Hearing Disorders, 55, 713-720.

Forbes-McKay, K. E., \& Venneri, A. (2005). Detecting subtle spontaneous language decline in early Alzheimer's disease with a picture description task. Neurological Sciences, 26, 243-254.

Giles, E., Patterson, K., \& Hodges, J. R. (1996). Performance on the Boston Cookie Theft picture description task in patients with early dementia of the Alzheimer's type: missing information. Aphasiology, 10, 395-408.

Goodglass, H., \& Kaplan, E. (1983). The assessment aphasia and relate disorders (2nd ed.). Philadelphia, PA: Lea and Febiger.

Groves-Wright, K., Neils-Strunjas, J., Burnett, R., \& O’Neill, M. J. (2004). A comparison of verbal and written language in Alzheimer's disease. Journal of Communication Disorders, 37, 109-130.

Hier, D. B., Hagenlocker, K., \& Shindler, A. G. (1985). Language disintegration in dementia: effects of etiology and severity. Brain and Language, 25, 117-133.

Im, E. J., Kwon, M., \& Sim, H. S. (2001). The informativeness and efficiency of the connected speech samples in Korean fluent aphasics. Korean Journal of Communication Disorders, 6, 374-391.

Jung, Y. H. (2009). A study for the informativeness and efficiency of spontaneous speech depending on task type in patients with Alzheimer's disease (Master's thesis). Ewha Womans University, Seoul, Korea.

Kang, Y. (2006). A normative study of the Korean-Mini Mental State Examination (K-MMSE) in the elderly. Korean Journal of Psychology: General, 25, 1-12.

Kempler, D., Curtiss, S., \& Jackson, C. (1987). Syntactic preservation in Alzheimer's disease. Journal of Speech, Language, and Hearing Research, 30, 343-350.

Kim, J. M., Yoon, M. S., Kim, S. J., Chang, M. S., \& Cha, J. (2012). Utterance types in typically developing preschoolers. Korean Journal of Communication Disorders, 17, 488-498.

Kim, J., Kim, H., Namkoong, K., Kim, S., \& Kim, D. (2006). Spontaneous speech traits in patients with Alzheimer's disease. Korean Journal of Communication Disorders, 11, 82-98.

Kwon, M., Kim, H., Choi, S. S., Na, D., \& Lee, K. H. (1998). A study for analyzing spontaneous speech of Korean adults with CIU scoring system. Korean Journal of Communication Disorders, 3, 35-49.

Lee, J. H., Lee, K. U., Lee, D. Y., Kim, K. W., Jhoo, J. H., Kim, J. H., ... \& Woo, J. 
I. (2002). Development of the Korean version of the Consortium to Establish a Registry for Alzheimer's Disease Assessment Packet (CERAD-K) clinical and neuropsychological assessment batteries. Journals of Gerontology Series B: Psychological Sciences and Social Sciences, 57, P47-P53.

Lee, K. (2002). Naming deficits in patients with dementia of the Alzheimer type (Master's thesis). Ewha Womans University, Seoul, Korea.

Lee, Y. M., \& Kim, H. (2001). An utterance analysis of convers at ions and picture description tasks of Korean adults. Korean Journal of Communication Disorders, 6, 1-11.

Mahoney, F. I. (1965). Functional evaluation: the Barthel index. Maryland State Medical Journal, 14, 61-65.

Martin, A., \& Fedio, P. (1983). Word production and comprehension in Alzheimer's disease: the breakdown of semantic knowledge. Brain and Language, 19, 124-141.

Morris, J. C. (1993). The Clinical Dementia Rating (CDR): current version and scoring rules. Neurology, 43, 2412-2414.

Nicholas, L. E., \& Brookshire, R. H. (1993). A system for quantifying the informativeness and efficiency of the connected speech of adults with aphasia. Journal of Speech, Language, and Hearing Research, 36, 338-350.

Nicholas, L. E., \& Brookshire, R. H. (1995). Presence, completeness, and ac- curacy of main concepts in the connected speech of non-brain-damaged adults and adults with aphasia. Journal of Speech, Language, and Hearing Research, 38, 145-156.

O'Bryant, S. E., Lacritz, L. H., Hall, J., Waring, S. C., Chan, W., Khodr, Z. G., ... \& Cullum, C. M. (2010). Validation of the new interpretive guidelines for the clinical dementia rating scale sum of boxes score in the national Alzheimer's coordinating center database. Archives of Neurology, 67, 746-749.

Petersen, R. C. (2004). Mild cognitive impairment as a diagnostic entity. Journal of Internal Medicine, 256, 183-194.

Petersen, R. C., Doody, R., Kurz, A., Mohs, R. C., Morris, J. C., Rabins, P. V., ... \& Winblad, B. (2001). Current concepts in mild cognitive impairment. Archives of Neurology, 58, 1985-1992.

Sohn, E. N., \& Park, S. H. (2008). A comparative study of discourse specification on type of dementia. Journal of Special Education and Rehabilitation Science, 47, 143-166.

Sohn, E. N., Kim, H. J., \& Park, S. H. (2007). Discourse analyses by Alzheimer's disease and right-hemisphere-damaged use analyze method main concept. Journal of Special Education and Rehabilitation Science, 46, 255-269.

Yi, B. W. (2015). Korean grammar for speech-language pathologists. Seoul: Hakjisa. 
Appendix 1. Boston Cookie-Theft picture의 주요개념 분석 기준(Hier, Hagenlocker, \& Shindler, 1985)

\begin{tabular}{lll}
\hline 행위자 & \multicolumn{1}{c}{ 행위 또는 상황 } & 채점 \\
\hline (1) 여자/엄마(the mother) & (1) 접시를 닦는다(washing dishes). & 각 주요개념에 해당하는 발화에 \\
(2) 소년(the boy) & (2) 떨어지다(falling down). & 1점씩 부여(총점 8점) \\
(3) 소년/아이들(the boy/the children) & (3) 과자를 꺼내다/훔치다(stealing or taking cookies). & \\
(4) 물(the water) & (4) 바닥에 쏟아지고 있다(the water running onto the floor). & \\
\hline
\end{tabular}




\section{국문초록}

\section{경도인지장애 및 알츠하이머형 치매 환자의 자발화 분석 척도의 유용성}

진천 ${ }^{1} \cdot$ 최현주 ${ }^{2} \cdot$ 이준영 3.4

${ }^{1}$ 나사렛대학교 재활복지대학원, ${ }^{2}$ 나사렛대학교 언어치료학과, ${ }^{3}$ 서울대학교 의과대학 정신건강의학교실, ${ }^{4}$ 서울특별시보라매병원 정신건강의학과

배경 및 목적: 본 연구는 일반 고령자, $\mathrm{MCI}, \mathrm{DAT}$ 환자를 대상으로 기존 연구에서 사용 빈도가 높았던 네 가지 분석 척도를 사용하여 자발화 수행에서의 집단 간 차이를 분석하고, 각 집단을 변별하는 데 가장 유용한 자발화 분석 척도를 알아보는 것을 목적으로 하였다. 방법: 연구 대상은 일반 고령자, MCI 환자, DAT 환자 각 30명씩 총 90명이었다. 연구 과제로는 Boston Cookie-Theft picture를 이용한 그림설명 과제를 사용하였으며, 자발화 분석 척도로는 CIU 낱말과 어절 비율, 주요개념, 발화당 내용어수 분석을 사용하였다. 결과: 첫 째, 네 가지 분석 척도 모두 집단 간 차이가 유의한 것으로 나타났으며, 일반 고령자 집단은 MCI 집단에서 비해 발화당 내용어수 분석에 서, MCI 집단은 DAT 집단에 비해 CIU 어절 비율 분석에서만 유의하게 수행이 높았다. 일반 고령자 집단은 DAT 집단에 비해 네 가지 분석 척도 모두에서 유의하게 수행이 높은 것으로 나타났다. 둘째, ROC분석 결과 그림설명 과제의 수행 차이가 유의하게 나타난 자발 화 분석 척도 모두 민감도와 특이도 측면에서 변별도가 유의하게 높은 것으로 나타났다. 논의 및 결론: 이러한 결과는 정상적인 노화, $\mathrm{MCI}, \mathrm{DAT}$ 로 진행하는 과정에서 이들의 언어 능력의 변화를 민감히 검출해낼 수 있는 자발화 분석 척도가 서로 상이함을 시사한다.

핵심어: 경도인지장애, 알츠하이머형 치매, 그림설명 과제, 자발화 분석 척도

본 연구는 2013년 정부(교육과학기술부) 재원인 한국연구재단(NRF-2013S1A5A8023389)과 2015년 한국언어청각임상학회 이승환장학금 지원에 의한 연구임.

본 연구는 제 1 저자의 석사학위논문(2015)을 요약한 것임.

\section{참고문헌}

강연욱(2006). K-MMSE (Korean-Mini Mental State Examination)의 노인 규준 연구. 한국심리학회지: 일반, 25, 1-12.

권미선, 김향희, 최상숙, 나덕렬, 이광호(1998). 한국 성인의 자발화 분석에 관한 연구: CIU 분석법을 중심으로. 언어청각장애연구, 3, 35-49. 김정미, 윤미선, 김수진, 장문수, 차재은(2012). 학령전기 일반아동의 발화 유형과 발화 종결기능 어미사용 특성. 언어청각장애연구, 17, 488-498. 김정완, 김향희, 남궁기, 김세주, 김덕용(2006). 알츠하이머형 치매환자의 발화 특성. 언어청각장애연구, 11, 82-98.

손은남, 김효정, 박선희(2007). 주요 개념 분석법을 이용한 알츠하이머성 치매 환자와 우반구 손상자의 담화 특성 비교. 특수교육재활과학연구, 46, 255-269.

손은남, 박선희(2008). 자발화를 통한 알츠하이머형 치매와 뇌혈관성 치매의 언어 특성 연구. 특수교육재활과학연구, 47, 143-166.

이규정(2002). 알쯔하이머성 치매환자의 이름대기장애에 관한 연구. 이화여자대학교대학원 석사학위논문.

이봉원(2015). 언어치료사를 위한 한국어문법. 서울: 학지사.

이영미, 김향희(2001). 대화와 그림설명과제를 통한 한국성인 발화의 비교 분석. 언어청각장애연구, 6, 1-11.

임은주, 권미선, 심현섭(2001). 경중도에 따른 유창성 실어증환자의 정보전달 능력에 관한 연구. 언어청각장애연구, 6, 374-391.

정윤희(2009). 알츠하이머치매 환자의 과제유형에 따른 정보 전달 능력에 관한 연구. 이화여자대학교대학원 석사학위논문.

최창선, 최현주(2013). 경도인지장애와 알츠하이머형 치매 환자의 이야기 이해 특성. 언어치료연구, 22, 159-180.

최현주(2011). 구어유창성과 그림설명과제를 통한 경도인지장애(MCI) 환자의 언어손상 검출. 언어청각장애연구, 16, 171-184.

최현주(2013). 건망형 경도인지장애 환자의 이름대기 및 담화 과제의 수행 특성. 언어치료연구, 22, 17-33.

최현주, 김지현, 이창민, 김재일(2013). 기억형 경도인지장애 환자의 의미적 측면에서의 언어장애 특성. 대한치매학회지, 12, 33-40. 